Copyright (C) 2015 by Academic Publishing House Researcher

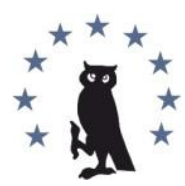

Published in the Russian Federation

European Researcher

Has been issued since 2010.

ISSN 2219-8229

E-ISSN 2224-0136

Vol. 91, Is. 2, pp. 79-85, 2015

DOI: $10.13187 /$ er.2015.91.79

www.erjournal.ru

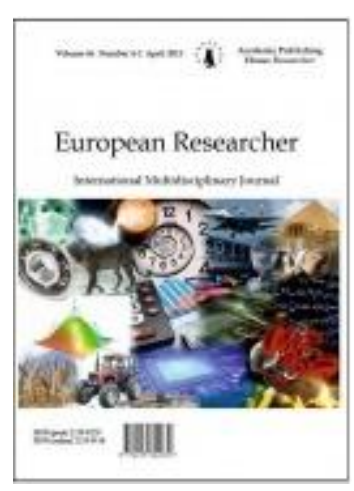

UDC $338 / 24$

\title{
Legal Provision of Food Security - as the Main Component of the National Security of the Republic of Kazakhstan
}

\author{
Valikhan M. Kaliyev \\ Varna Free University “Chernorizets Hrabar”, Bulgaria \\ Chayka Resort, Varna, 9007 \\ PhD student \\ E-mail: valihan-777@mail.ru
}

\section{Abstract}

This article examines the legal problems of food security - as the main component of the national security of the Republic. The problem of food security is the top priority of economic strategy policy of any state, the effectiveness of the solution of which depends not only social but also political, ethnic stability in the society. Author analyzing existing legislation in the field of food security, identifies weaknesses and gaps, suggests ways to improve it.

Keywords: Food Security; The Republic of Kazakhstan; issue; national security; resources; the agricultural sector; legislation; Codex Alimentarius; food, health of the nation.

\section{Введение}

Проблема продовольственной безопасности страны, является важнейшим приоритетом экономической стратегии политики любого государства, от эффективности решения которой зависит не только социальная, но и политическая, межнациональная стабильность в обществе.

Продовольственная безопасность, являясь неотъемлемым элементом национальной безопасности, во многом также зависит от государственных ресурсов, направленных на недопущение дисбаланса в рыночной, производственной и социальной среде страны. Формирование государственных ресурсов по всем видам продовольственных товаров, государственных ресурсов зерна и других стратегически важных продуктов сельского хозяйства в нужных объемах в зависимости от потребности населения, способно обеспечить продовольственную безопасность.

В условиях мирового финансового кризиса, затронувшего и аграрный сектор экономики, возникла реальная угроза глобальной продовольственной безопасности, что требует реформирования существующих и разработки новых механизмов ее обеспечения на международном и национальном уровнях. Экономическая, политическая и социальная безопасность в современном мире базируется на трех других аспектах безопасности продовольственной, энергетической и финансовой. По данным организации объединенных наций в мире более 925 млн человек страдают от голода. Это составляет 12,5 \% населения мира (каждый восьмой человек). Из них подавляющее большинство - 852 млн человек проживают в развивающихся странах, где недоедают 14,9\% населения. Количество 
голодающих в мире по-прежнему неприемлемо велико. Учитывая нынешние темпы прироста населения, к 2050 году мировое производство продуктов питания должно возрасти на 70 \%, а население мира должно к этому времени составить 9 миллиардов человек [1].

Во многом неустойчивое и чреватое потрясениями положение на мировых продовольственных рынках связано с тем, что система мирового производства пищевой продукции зависима не только от глобальных и локальных погодных и климатических факторов, но и от состояния далеко не совершенной мировой финансовой системы.

Происходящее в настоящее время восстановление агропромышленного комплекса происходит в весьма непростых условиях. На них крайне значительное влияние оказывают изменения в юридическом поле, на основании которых должно быть усовершенствовано казахстанское законодательство, в частности, регулирующее вопросы в области земельного законодательства, ветеринарии и фито санитарии, обеспечения пищевой безопасности [2]. Это связано, прежде всего, с формированием Таможенного союза и принятием соответствующих рамочных договоренностей.

\section{Результаты}

В Послании Президента Республики Казахстан Н.А. Назарбаева народу Казахстана 2008 года «Повышение благосостояния граждан Казахстана - главная цель государственной политики» продовольственная безопасность объявлена приоритетным направлением государственной политики страны [3]. Продовольственная безопасность республики в целом и входящих в ее состав регионов является составной частью экономической безопасности в системе национальной безопасности страны, и в этом качестве характеризует экономическую устойчивость и независимость существующей системы, а также ее способность обеспечивать элементарные первичные потребности своих граждан без ущерба национально-государственным интересам. При этом продовольственная безопасность не ограничивается рамками только экономической безопасности, так как находится в тесной взаимосвязи с другими аспектами национальной безопасности.

Проблемы продовольственной безопасности требуют также глубинных исследований в области сельского хозяйства. Скоординированная работа в области биотехнологий направленные на улучшение сельскохозяйственных культур, инновационные стратегии в сфере переработки и производства в сельском хозяйстве, стимулирование внедрения новых технологий в пищевой промышленности и привлечением инвестиций в научноисследовательские проекты в этой сфере могут служить гарантом продовольственной безопасности Республики Казахстан.

Приход дешевого и не всегда качественного импортного продовольствия на внутренний рынок, ослабит позиции казахстанских сельскохозяйственных производителей, а затем спровоцирует рост цен на продовольствие, что неблагоприятно скажется на доходах как городских, так и сельских жителей и ухудшит ситуацию с экономической доступностью продовольствия. В соответствии с этой угрозой, законодательство должно определить жесткие барьеры для предотвращения попадания на наш рынок опасной и недоброкачественной пищевой продукции, как в виде сырья для ее производства, так и в виде продуктов, готовых к употреблению. Эта задача имеет первоочередное значение. Кодекс Алиментариус, или пищевой кодекс, стал глобальным ориентиром для потребителей, производителей и переработчиков пищевых продуктов, национальных органов по контролю качества пищевых продуктов и международной торговли пищевыми продуктами. Этот кодекс оказал огромное влияние на взгляды и подходы производителей и переработчиков пищевых продуктов и на уровень информированности конечных пользователей - потребителей. Его влияние распространяется на все континенты, а вклад в охрану здоровья населения и защиту добросовестности в торговле пищевыми продуктами поистине не поддается измерению. Страны с низким и средним уровнем доходов указали, что эти стандарты очень важны для охраны здоровья потребителей, поскольку они обеспечивают безопасность пищевых продуктов, будь то собственного производства или импортных, и для облегчения торговли, как на внутренних, так и на международных рынках. Страны с высоким уровнем доходов и более развитыми внутренними системами законодательства и контроля качества пищевых продуктов больше значения придавали 
роли Кодекс Алиментариус в облегчении экспорта и обеспечении безопасности импорта пищевых продуктов [4].

К национальным интересам Республики Казахстан в агропродовольственной сфере можно отнести: обеспечение необходимого объема собственного производства продуктов питания; поддержание на нормативном уровне государственного продовольственного резерва; обеспечение соответствия качества производимых и реализуемых продуктов питания стандартам качества и безопасности пищевых продуктов; обеспечение необходимого прожиточного минимума, достойного уровня и высокого качества здоровой жизни населения; расширение производства конкурентоспособной продовольственной продукции с ориентацией на экспорт; осуществление государственного контроля рынка продовольствия (в том числе учета и контроля производства, внешних и внутренних поставок, запасов продуктов питания). Согласно Закону Республики Казахстан «О государственном регулировании развития агропромышленного комплекса и сельских территорий» критериями обеспечения продовольственной безопасности являются:

1) физическая доступность продовольственных товаров;

2) экономическая доступность продовольственных товаров;

3) гарантия безопасности пищевой продукции.

В обобщенном виде состояние продовольственной безопасности страны определяется: физической доступностью продовольствия - наличием продуктов питания на всей территории страны в каждый момент времени и в необходимом ассортименте, то есть наличие продовольственных товаров на всей территории республики в каждый момент времени и в объемах, достаточных для удовлетворения потребностей населения; экономической доступностью продовольствия - уровнем доходов независимо от социального статуса и места жительства гражданина, позволяющим приобретать продукты питания, по крайней мере, на минимальном уровне потребления, то есть возможность приобретения населением продовольственных товаров в соответствии с физиологическими нормами потребления при существующих структуре потребления продовольственных товаров, системе цен, уровне доходов, социальных пособий и льгот; безопасностью продовольствия для потребителей - предотвращением производства, реализации и потребления некачественных пищевых продуктов, способных нанести вред здоровью населения [5].

Показателями устойчивости системы обеспечения продовольственной безопасности является уровень качества и безопасности продуктов питания.

В последние годы эта проблема приобрела особую важность, так как наблюдается низкий уровень качества поступающих на рынок отечественных продуктов питания.

Не меньшей проблемой является поступление на отечественный продовольственный рынок импортной продукции, которая не всегда отвечает требованиям качества, соответствует срокам хранения и безопасна для здоровья. При этом продукция такого качества в силу низкой покупательской способности обладает большим спросом. Нередко такая продукция производится из генетически модифицированного сырья. Все это способствует ухудшению здоровья нации.

Наличие подобных факторов обусловлено, в первую очередь, неэффективной системой государственного контроля и надзора за качеством продуктов питания. [6, С. 13]

Наиболее распространено определение продовольственной безопасности, как способности государства гарантировать удовлетворения потребности населения в качественном продовольствии на уровне, при котором обеспечивается его нормальная жизнедеятельность. В то же время в ряде публикаций проблема продовольственной безопасности фактически сводится к проблеме само обеспечения страны продовольствием и, как следствие, к состоянию отечественного аграрного сектора и уровню аграрного протекционизма. Однако продовольственная безопасность определяется не только этими факторами, но и общеэкономической ситуацией в стране. Низкие реальные доходы значительной части населения делают продовольствие недоступным в необходимом для нормального жизнеобеспечения объеме, негативно сказываются на качестве питания. Слабый платежеспособный спрос населения ограничивает возможности развития национального производства продуктов питания. Обеспечение национальной безопасности - одна из главных функций государства. Продовольственная безопасность, в свою очередь, 
важнейшая составляющая национальной безопасности любой страны. Продовольственная безопасность - важнейший элемент экономической безопасности. Значение продовольственной безопасности обусловлено ролью продовольственного обеспечения для поддержания социально-экономической стабильности в обществе. При этом важны физическая и экономическая доступность продовольствия для населения, уровень потребления, качество и структура рациона питания, качество продуктов питания. Не менее важны и проблемы само обеспечения страны продовольствием, независимости от импорта продуктов питания, формирования государственных резервов продовольствия на случай чрезвычайных ситуаций (стихийных бедствий, военных конфликтов, эпидемий и так далее) и для оказания продовольственной помощи неимущим слоям населения. Таким образом, продовольственная безопасность обуславливается уровнем экономического развития страны в целом и агропродовольственного сектора, в частности социальной, агропродовольственной и внешнеэкономической политикой государства, а также зависит от наличия эффективной системы контроля качества продовольствия [7, с. 86-87].

В целом продовольственная безопасность - это понятие, имеющее политические, социальные и экономические аспекты. При этом особое значение имеет вопрос о роли государства в регулировании социально-экономических процессов в этой сфере, формах и методах такого регулирования.

Продовольственную безопасность следует рассматривать с точки зрения надежности продовольственного обеспечения населения (стабильности формирования продовольственных ресурсов и их потребления), так и с точки зрения поддержания внутренних и внешних национальных интересов, суверенитета страны в продовольственной сфере (недопущение критической зависимости Казахстана от зарубежных стран или их сообществ в вопросах, связанных с продовольствием, защита экономических интересов отечественных потребителей и производителей, обеспечение их интересов). Кроме того, существует еще один аспект продовольственной безопасности - это готовность государства к предотвращению и ликвидации нарушений системы обеспечения населения продуктами питания, обусловленных чрезвычайными продовольственными ситуациями [6. с. 9-10].

Ключевую роль в обеспечении продовольственной безопасности играют меры, направленные, во-первых, на обеспечение роста реальных доходов населения, повышение его жизненного уровня; во-вторых, на устойчивое развитие и функционирование агропродовольственного сектора экономики страны; в-третьих, на эффективное регулирование внешней торговли сельскохозяйственной продукцией, сырьем и продовольствием, и прежде всего их импорта, с целью защиты внутреннего продовольственного рынка, экономических интересов отечественных товаропроизводителей от недобросовестной конкуренции.

\section{Выводы}

Анализируя действующее законодательство в области обеспечения продовольственной безопасности и качества пищевых продуктов можно сделать следующие выводы:

Следует отметить, что в развитых странах мира для обеспечения продовольственной безопасности приняты специальные законодательные акты. На уровне республики основным инструментом механизма обеспечения продовольственной безопасности, должна быть законодательная база. Необходимо отметить, что обеспечение продовольственной безопасности - основной составляющей национальной безопасности, - в республике регламентируется отдельными законодательными актами, подзаконными актами и техническими регламентами, отсутствует целостный нормативный правовой документ, где были бы четко обозначены цели, задачи, субъекты, меры по обеспечению продовольственной безопасности государства. В свете предстоящих изменений, происходящих в мировой экономической системе: роста цен на все продовольственные товары, нехватки продовольствия, кризисных явлений, затронувших все сектора экономики, - возникает серьезная угроза национальной продовольственной безопасности, что обуславливает необходимость разработки и принятия нормативного документа, регламентирующего механизм обеспечения продовольственной безопасности Республики Казахстан. Следует отметить, что принимаемый закон должен соответствовать Кодексу Алиментариусу, или пищевому кодексу, который является глобальным ориентиром для 
потребителей, производителей и переработчиков пищевых продуктов, национальных органов по контролю качества пищевых продуктов и международной торговли пищевыми продуктами.

В настоящее время функции государственного контроля и надзора за качеством и безопасности пищевых продуктов осуществляется разными государственными подразделениями, такими как, государственная санитарно-эпидемиологическая служба, государственная ветеринарная служба и комитет технического регулирования и метрологии, министерства здравоохранения и социального развития Республики Казахстан и другие. Это создает административные барьеры для отечественных товаропроизводителей и ведет к росту потребительских цен на продовольствие, а также размывает ответственность за достижение конечного результата - обеспечение безопасности продуктов питания для здоровья и жизни населения. В целях обеспечения безопасности и качества продуктов питания следует создать централизованный орган государственного контроля и надзора за качеством и безопасности пищевых продуктов при Министерстве сельского хозяйства Республики Казахстан. Учитывая актуальность и необходимость разработки новой аграрной политики государства, а также высокую ответственность перед населением страны за продовольственное обеспечение, предлагается преобразовать Министерство сельского хозяйства Республики Казахстан в Министерство сельского хозяйства и продовольственной безопасности Республики Казахстан. Также, настоящее Министерство должно работать в тесной взаимосвязи с Продовольственной и сельскохозяйственной организацией Объединенных Наций (ФАО), которая занимает ведущую роль в международной деятельности направленной на борьбу с голодом.

Необходимо внедрять системы социальной защиты, чтобы дать возможность наиболее уязвимым слоям населения участвовать в экономическом процессе, вкладывать и получать выгоду. Меры социальной защиты могут внести вклад в улучшение питательной составляющей в рационе питания маленьких детей - инвестиции в будущее, чтобы вырастить более здоровое, сильное и образованное поколение. Голод и недоедание можно уничтожить с помощью эффективных мер социальной защиты в комплексе с всеобщим экономическим ростом.

А также на основании уже принятого закона должна быть разработана комплексная программа продовольственной безопасности, которая будет определять механизм ее обеспечения не только с позиций физической, но и экономической доступности продовольствия. Необходимо законодательное гарантирование определенного уровня цен на продовольственные товары. Это регулирование должно происходить путем устранения предельных надбавок к закупочной цене оптовых ярмарок. При этом следует стимулировать сокращение излишних посреднических звеньев и создать необходимую правовую базу для расширения прямых связей с оптовым звеном. Законодательство должно включать регламентацию по установлению цен на технику, оборудование для села, топливноэнергетические ресурсы, транспортные тарифы, минеральные удобрения, по ограничению монопольного поведения организаций по ремонту техники и по оказанию иных производственных услуг.

Для обеспечения продовольственной безопасности необходимо: развитие товаропроизводительной составляющей, в том числе создание крупных логистических центров, создание мощной мониторинговой системы за качеством товаров поступающих на внутренний рынок.

\section{Примечания:}

1. Положение дел в связи с отсутствием продовольственной безопасности в мире // www.fao.org/icatalog/inter-e.htm

2. Продовольственная безопасность региона как составляющая безопасности экономики Казахстана при вступлении в ВТО (на примере ВКО) // Вестн. ВКГТУ. УстьКаменогорск: ВКГТУ, 2006. № 4. С. 96-107 (в соавторстве).

3. Послание Президента Республики Казахстан Н.А. Назарбаева народу Казахстана 2008 года «Повышение благосостояния граждан Казахстана - главная цель государственной политики» // Политика и право. 
4. Codex Alimentarius Commission. Procedural Manual. Sixteenth edition. Joint FAO/WHO Food Standards Programme// http://www.fao.org/icatalog/inter-e.htm

5. Волончин К.В., Еделев Д.А., Кантере В.М. Технологии обеспечения безопасности и качества продуктов // Пищевая промышленность. 2010. № 5. С. 16-17.

6. Киршке Д. Международная аграрная экономика и аграрная политика // Международный сельскохозяйственный журнал. 2000. № 6. С. 5-13.

7. Аграрная политика / А.П. Зинченко, В.И. Назаренко, В.В. Шайкин и др.; Под ред. А.П. Зинченко. М.: КолосС, 2004. 304 с.

8. Kalinichenko V. Biogeosystem Technique as a Problem // Biogeosystem Technique, 2014, Vol.(1), № 1, pp. 4-19. DOI 10.13187/bgt.2014.1.4

9. Minakir P.A., Vlasyuk L.I., Goryunov A.P. Technological and Economic Approaches in Long-term Regional Forecasting (Russian Far East) // European Journal of Economic Studies, 2012, Vol.(2), № 2, pp. 117-130.

10. Samigullina G.Z. Secure Methods of Assessing Toxicity of Waste in Food Industry of the Udmurt Republic // Russian Journal of Biological Research, 2014, Vol. (1), № 1, pp. 69-72.

\section{References:}

1. Polozhenie del $\mathrm{v}$ svyazi $\mathrm{s}$ otsutstviem prodovol'stvennoi bezopasnosti $\mathrm{v}$ mire // www.fao.org/icatalog/inter-e.htm

2. Prodovol'stvennaya bezopasnost' regiona kak sostavlyayushchaya bezopasnosti ekonomiki Kazakhstana pri vstuplenii v VTO (na primere VKO) // Vestn. VKGTU. Ust'-Kamenogorsk: VKGTU, 2006. № 4. S. 96-107 (v soavtorstve).

3. Poslanie Prezidenta Respubliki Kazakhstan N.A. Nazarbaeva narodu Kazakhstana 2008 goda «Povyshenie blagosostoyaniya grazhdan Kazakhstana - glavnaya tsel' gosudarstvennoi politiki» // Politika i pravo.

4. Codex Alimentarius Commission. Procedural Manual. Sixteenth edition. Joint FAO/WHO Food Standards Programme// http://www.fao.org/icatalog/inter-e.htm

5. Volonchin K.V., Edelev D.A., Kantere V.M. Tekhnologii obespecheniya bezopasnosti i kachestva produktov // Pishchevaya promyshlennost'. 2010. № 5. S. 16-17.

6. Kirshke D. Mezhdunarodnaya agrarnaya ekonomika i agrarnaya politika // Mezhdunarodnyi sel'skokhozyaistvennyi zhurnal. 2000. № 6. S. 5-13.

7. Agrarnaya politika / A.P. Zinchenko, V.I. Nazarenko, V.V. Shaikin i dr.; Pod red. A.P. Zinchenko. M.: KolosS, 2004. 304 s.

8. Kalinichenko V. Biogeosystem Technique as a Problem // Biogeosystem Technique, 2014, Vol.(1), № 1, pp. 4-19. DOI 10.13187/bgt.2014.1.4

9. Minakir P.A., Vlasyuk L.I., Goryunov A.P. Technological and Economic Approaches in Long-term Regional Forecasting (Russian Far East) // European Journal of Economic Studies, 2012, Vol.(2), № 2, pp. 117-130.

10. Samigullina G.Z. Secure Methods of Assessing Toxicity of Waste in Food Industry of the Udmurt Republic // Russian Journal of Biological Research, 2014, Vol. (1), № 1, pp. 69-72.

УДК $338 / 24$

\section{Правовое обеспечение продовольственной безопасности - как основной составляющей национальной безопасности Республики Казахстан}

Валихан Муратович Калиев

Варненский свободный университет им.Черноризца Храбра, Болгария

г. Варна 9007, к.к. Чайка

Соискатель

E-mail: valihan-777@mail.ru

Аннотация. В настоящей статье рассматриваются проблемы правового обеспечения продовольственной безопасности - как основной составляющей национальной безопасности 
Республики. Проблема продовольственной безопасности страны является важнейшим приоритетом экономической стратегии политики любого государства, от эффективности решения которой зависит не только социальная, но и политическая, межнациональная стабильность в обществе. Автор анализируя действующее законодательства в области обеспечения продовольственной безопасности, выявляет недостатки и пробелы, предлагает пути его совершенствования.

Ключевые слова: продовольственная безопасность; Республика Казахстан; проблема; национальная безопасность; ресурсы; аграрный сектор; законодательство; Кодекс Алиментариус; продукты питания, здоровье нации. 